1. Отто Р. Священное. Об иррациональном в идее божественного и его соотношении с рациональным // LIBKING : [сайт]. URL: https://libking.ru/books/sci-/sci-philosophy/376168rudolf-otto-svyashchennoe.html (дата обращения: 23.09.2020).

2. Хоружий С. С. Синергийная антропология. Томские лекции // Вестн. Том. гос. ун-та. 2008. № 1 (2). С. 54-88.

3. Букина Н. В. Культурный код как язык культуры // Вестн. ЧитГУ // Cyberleninka : [сайт]. URL: https://cyberleninka. ru/article/n/kulturnyy-kod-kak-yazyk-kultury/viewer (дата обращения: 23.09.2020).

4. Ремарк Э. М. Время жить и время умирать // Ремарк Э. М. Собрание сочинений : в 11 т. М. : ВИТА-ЦЕНТР, 1992. Т. 6. $320 \mathrm{c}$.

5. Фолкнер У. Избранные произведения : в 3 т. Т. 1. По ту сторону рая. М. : Художественная литература, 1977. C. 31-284.

УДК 130.2

Науч. спец. 09.00.13

DOI: $10.36809 / 2309-9380-2020-28-37-40$

\section{ТИПЫ ВЛАСТИ И МОДЕРНИЗАЦИИ В ФОРМИРОВАНИИ ЧЕЛОВЕКА}

В статье показано, что азиатская (японская) модернизация оказалась вызовом для европейской, этот вызов породил диверсификацию заводов, изменение системы свободного времени, а в настоящее время - обращение к концепции эмоционального интеллекта. Разъясняется на основании анализа различия обществ и модернизаций, почему азиатские новации не переносятся на европейскую и американскую почву, а также описывается проектирование новых способов подготовки лидеров и активных работников.

Ключевые слова: типы модернизации, азиатская модернизация, кружки качества, система канбан, сети власти и коммуникации.
6. Пылаев М. А. Философия религии в феноменологии Рудольфа Отто // Вестн. ПСТГУ І: Богословие. Философрия. 2011. Вып. 6 (38). С. 59-74.

7. Забияко А. П. Сакральное как категория феноменологии религии М. Элиаде // Мирча Элиаде : [сайт]. URL: http:// eliade.upelsinka.com/cr3.htm (дата обращения: 23.09.2020).

8. Тосфллер Э. Третья волна. М. : АСТ, 2002. 776 с.

9. Яковлева Е. Митрополит Иларион: С коронавирусом лучше перестраховаться, чем недооценить степень угрозы // Российская газета. Федеральный выпуск. 2020. № 59 (8113). 18 марта. URL: https://rg.ru/2020/03/17/mitropolit-ilarion-skoronavirusom-luchshe-perestrahovatsia-chem-nedoocenit. html (дата обращения: 23.09.2020).

10. Духовные лидеры ислама и православия Татарстана призвали верующих бороться с коронавирусом // YouTube : [видеохостинг]. URL: https://www.youtube.com/ watch?v=abDNmf8uisw (дата обращения: 23.09.2020).

(C) Нефёдова Л. К., 2020

\title{
TYPES OF AUTHORITY AND MODERNIZATION IN HUMAN FORMATION
}

The article shows that the Asian (Japanese) modernization turned out to be a challenge for the European one, this challenge gave rise to the diversification of factories, a change in the system of free time, and nowadays - an appeal to the concept of emotional intelligence. It is explained on the basis of an analysis of the differences between societies and modernizations, why Asian innovations are not transferred to European and American soil, and the author also describes the design of new methods of training leaders and active workers.

Keywords: types of modernization, Asian modernization, quality circles, the system of Kanban, network of authority and communication.

Сопоставление типов модернизации показывает, что в Азии этот процесс идет иначе, чем в Европе, причем азиатская и, в частности, японская модернизация существенно влияют на американскую, что особенно наглядно представлено в феномене японского экономического чуда 1955-1975 гг.

Прояснение того, чем именно различаются модернизации и почему они не переносятся на другую почву, показывает концепция М. Манна [1, с. 18], разделяющего сети четырех типов власти. Эта модель делает видимыми ошибки догоняющей стороны.

Концепция сетей власти позволяет по-новому посмотреть на модернизацию вообще и сделать вывод, что планирование стратегии модернизации требует привязки оной к национальной и локальной традиции места внедрения, причем модернизация должна вырабатываться в точках пересечения сетей власти, путем создания новых «ячеек сети», из которых произрастают уже адаптированные к местным условиям проекты.

Это требует по-новому подойти к подготовке кадров к такому типу модернизации, в том числе русского типа.

1. Япония и Америка: сопоставление типов модернизации

Азиатская модернизация, с антропологической стороны, опирается на высококвалифицированного работника, а с культурной - на «западную технику, японский дух». Японский рабочий в этой модернизации выступает источником новаций, технических и организационных. Японская модернизация идет не только сверху, но и снизу.

Американская модернизация идет сверху, от инженера и капиталиста, при низкоквалифицированном рабочем. При 
этом надо различать модернизацию производства и потребления. Если американская индустриализация идет сверху, то потребление - снизу, фермер может не покупать то, что ему навязывают. Современный потребитель не может отказаться от покупок.

Американская промышленность XIX в., будучи ограничена внутренним рынком из-за отсутствия колоний, производит товары для своего потребителя, для фермера, и вынуждена ориентироваться на него. Давление нового типа потребителя преобразует требования и производство в Америке [2, с. 161].

Столкновение США, после Второй мировой войны, С японским чудом, связываемым ими с системой пожизненного найма, порождает попытки перенять японский опыт внутри американского. Это выразилось в двух видах интенсификации. Первая протекала на огромных заводах, когда за счет массовости экономятся затраты управленческого труда, вторая за счет изменения организации технологии рабочим.

Первый тип интенсификации порождает автоматизацию финансов, для чего используется компьютер или управляющее звено машины (первая его задача: расчет зарплаты на большом заводе). Другая организационная новация при сокращении размера заводов наблюдается в организации цепочки производителей, когда определенный тип деталей, если это выгодно, передавался в производство поставщикам. Уменьшение размера заводов, безусловно, подразумевало и социальный аспект в эпоху борьбы двух мировых систем, разукрупнение заводов означало рассеивание пролетариата и уничтожение его возможности к организации в профсоюзы. На малых предприятиях рабочие не объединяются в классовые организации.

Японская модернизация показывает иной тип интенсификации. Японский работник вырабатывает систему канбан. Есть табло, на котором показана динамика движения предметов труда в цехах, каждый рабочий представляет себе, как и что происходит, и встраивается в этот ритм. Например, рабочий решает сделать перерыв и отдохнуть, пока его предметы труда задерживаются. Он посылает заявки на поставку необходимых предметов, когда собирается работать. Он не простаивает, а на заводе нет складов, предметы труда плавно переходят от одного станка к другому. Сокращение площади завода при ликвидации складов, экономия на перемещение предметов за счет нового типа логистики дает огромную экономию внутри самого производства.

Наконец, японский работник получает выгоду от замены себя самого на автомат. Его зарплата увеличивается с каждым разом, после того как он себя заменяет. Зарплата тут организована не сдельно, как в США, Европе и СССР, а пожизненно. Если работник себя сократил, то он как бы капитализировал свой труд. Автомат его заменяет, но он получает большую зарплату и заинтересован заменить себя на новом месте: во-первых, чтобы не повторять рутинную работу, во-вторых, чтобы больше зарабатывать. Это основание знаменитых кружков качества, когда рабочие после работы остаются, чтобы усовершенствовать свое рабочее место, свой процесс производства, приглашают инженеров и обучаются себя заменять без отрыва от производства. Это напоминает политехническое образование, которое в нача- ле советской индустриализации внедрялось в СССР. Если рабочий многократно проходит такую автоматизацию своего труда, он получает большую зарплату и ценен, он обладает большей квалификацией и уровнем образования и может всё более самостоятельно и автономно себя заменять. Такие рабочие определяет политику внедрения инноваций в производство в Японии. Причем они не только могут, но и хотят делать инновации. И в системе канбан, и в системе кружков качества ключевым становится интерес рабочего к этим новациям [3, с. 183].

Как пытаются этот интерес пробудить американцы в своем работнике? Они вводят систему «свободного труда»: работник может приходить, когда хочет, и работать, сколько хочет, но тогда он получает, сколько сделал, т. е. свобода работы, но не интенсификация.

А. Тоффрлер выделяет три волны модернизации: в первой выигрывает тот, кто производит быстрее, это эпоха дефицита; во второй выигрывает тот, кто производит качественнее, это эпоха переполнения рынка и перепроизводства и периодических кризисов капитализма; в третьей - руководители производства начинают борьбу за лучших работников, выигрывает тот, кто привлекательнее для хорошего работника [4, с. 258].

Тоффлер отмечает экономическую сторону привлекательности труда, точнее критерий привлекательности труда на этой фирме. Он замечает, что японский рабочий $80 \%$ своих сбережений хранит на счету той фрирмы, в которой работает, т. е. связывает свое благосостояние с ней. Это в понимании американца совладение: рабочий, вкладывающий свои деньги в акции, становится совладельцем и должен получить экономический мотив работать лучше, работая на себя. В США 80 \% сбережений работников находятся вне рамок той фирмы, в которой они работают: «нельзя хранить яйца в одной корзине», т. е. американец четко разделяет свое благосостояние и собственность фирмы. Покупка акций не помогает запустить инициативу работника.

После экономических ресрорм, диверсификации производства, когда была интенсифицирована модернизация с организационной и технической стороны, но не была подключена рабочая инициатива, американцы меняют основы научной организации труда: теперь она вместо традиционной опоры на когнитивный интеллект, или IQ (далее КИ), переходит к опоре на эмоциональный интеллект $E Q$ (далее - ЭИ). ЭИ предполагает пробуждение инициативы работника, зависимость его успешности от активности управления своими эмоциями, эмоциями других и группы. В концепции ЭИ [5, с. 24] утверждается, что более успешными становятся люди, которые обладают высоком ЭИ, а не КИ, причем она подразумевает разрыв между двумя типами интеллекта.

Итак, если в японской экономике система сама отбирает в будущем успешных работников, то в США успешные работники достигают успеха, создавая успешные фирмы. Но по мере роста эти фирмы сталкиваются с дефицитом самих работников.

Отметим, что ни технологические новации инженерного и научного типа, ни модификация собственности типа продажи акций не заинтересовывают работника становиться инициатором внедрения новаций в производстве и актив- 
ным работником в плане превращения функционирования в развитие.

Подобным же образом формируется система поиска молодых лидеров в современной России, тренинги для предпринимателей убеждают последних, что надо искать работников с ЭИ, которые развиваются, активны, проявляют инициативу, создают заражающую позитивом атмосферу в коллективе, т. е. идет целенаправленный поиск и привлечение активных людей. Однако существенно отстает система их подготовки в школе и вузе. Можно в целом этот интерес к лидерам сфрормулировать как культ «гена желания». Ведь лидер желает создавать, но лидеров оказывается в нашем обществе мало, подтверждаются цифры А. Тоффлера, что пассионариев, или людей будущего, - $2 \%$, субпассионариев - 18 \%, а 80 \% людей пассивны и всегда следуют за лидером [6, с. 344].

2. Четьре сети власти: непереносимость модернизации

Иной подход к осмыслению этих процессов содержится в концепции М. Манна. В ней формулируется идея о сети четырех властей: экономической, политической, военной и идеологической. Оказывается, что эти власти действуют параллельно, каждая формирует свои сети автономного воздействия, но одна из властей может доминировать. Например, в Римской империи доминировала военная сила. Легионеры несли с собой строительный инструмент и строили дороги, поселки, т. е. военная власть контролировала политическую, самим расположением легионов подавляла возможность восстания, воздействовала на экономику, легионеры становились землевладельцами и строили дороги для интенсификации торговли. Христианство перестраивает власть в доминирование идеологии, например, когда возникает королевство франков, оно быстро разваливается, но Европа сохраняет единство идеологическое, т. е. религиозное.

Каждый тип власти подразумевает собственные клетки, которые могут соединяться, сливаясь в интегральную клетку. Например, клеткой экономики в фреодальной Европе был город, ярмарка, тут сосредоточены рынки, ремесленники; клетка политическая и отчасти военная - замки, тут элита и военное управление; центр идеологической власти монастыри, хотя они занимались и хозяйством. С идеологической властью тесно связана грамотность. М. Манн не выделяет образовательную власть, а подчиняет ее идеологии. В настоящее время в развертывании четвертой технологической, или информационной, революции образование становится отдельной властью, подразумевающей свои институты и клеточки как места развития [1, с. 744].

C позиции этой концепции понятно, что трансформация производства в США происходит путем доминирования политической и экономической власти и побуждения, а в Японии существенную роль играет идеологическое воздействие.

При анализе роли религии в возникновении капитализма традиционно обращаются к идеям М. Вебера, не то чтобы он напрямую доказал это влияние, но он показал, во-первых, разное воздействие религии на экономику, во-вторых, предрасположенность некоторых религий к капиталистическому типу организации жизни человека.
Концепция М. Манна делает видимым разность культур в их воздействии на формирование активности человека. Оказывается, что при повышении активности одного фактора, например экономического, активными становятся $2 \%$ людей, при соединении двух фракторов - 20 \%, а при взаимоусилении трех - 80 \% населения становятся активными. В выработке такой стратегии применения власти и управления формированием человека можно увидеть перспективу дальнейшего развития и, наконец, ответ на вызов японской и азиатской модернизации.

3. Исторический анализ модернизаций и смена ее проблем: отрицание исторической эфффективности культурной револющии

Развитие не технолого-экономического типа, а типа, опирающегося на местные сети власти и коммуникации, в итоге должно привести к тому, что развитие не прекратится при выходе из технопарка или бизнес-инкубатора, не будет деградировать, а будет легко вживаться в среду, куда оно внедряется.

Европейская модель модернизации, или сверхиндустриализации, строится на капитализации производства и управлении им сверху, со стороны хозяина и капитала. Страны первого эшелона индустриализации, так называемые старые капиталистические страны: Франция, Англия, прошли сначала переход в капиталистическое производство сельского хозяйства, а потом промышленности, а страны второго эшелона: Германия, царская Россия, начинали модернизацию с промышленности, с заимствования крупных предприятий из передовых стран [7].

Второй тип индустриализации порождает империализм и ведет к революции, потому что собственная страна, ее крестьянство становится внутренней колонией для промышленности, для которой необходимо разрушение прежнего типа организации земледельцев, чтобы они разорялись и стали свободной рабочей силой. В Англии рабочая сила исходно свободная, а в России она становилась вынужденно свободной. Разорение крестьянства стало проблемой, чреватой революцией, но при этом условием сверхиндустриализации. Более того, модернизация по-европейски предполагает культурную революцию, которая действует разрушительно на традиционную культуру.

Азиатская модернизация (Япония, четыре азиатских тигра - Южная Корея, Гонконг, Тайвань, Сингапур, и Индия) не производит культурной революции, а наоборот усиливает местную культуру и «работает» в направлении заинтересованности непосредственного работника в интенсификации и автоматизации их труда. Это сохраняет человека традиции в стране, не чревато социальными конфоликтами и меняет способ воспроизводства кадров для модернизации.

Итак, азиатская модернизация показывает, что не демократия и не создание обездоленной свободной рабочей силы - главный критерий ее успешности, а привязка к типу человека и сетям власти, уже имеющимся в культуре, и создание новых, адаптированных к культуре «клеточек развития» модернизационных проектов. При этом происходит насыщение их активными, по законам местной традиции, рабочими, без культурной революции. Такая азиатская модернизация на Запад не переносится. Она не переносима и в Россию. 
ФИЛОСОФИЯ

4. Вывод по «клеткам развития» в соотношении с проблемой человека

Сети коммуникации и власти показывают возможности организации мест (клеток) развития и привязки модернизации к локальной культуре и типу человека. При воспитании же человека следует создавать видение сетей и мест развития у ученика заранее, дабы сделать его стремящимся к саморазвитию.

Основная проблема, на наш взгляд, состоит в том, что ищут деловых лидеров, способных управлять своими эмоциями и эмоциями подчиненных, а нужны лидеры, создающие коллективы и управляющие ими.

Филососрская антропология способна увидеть человека за технологическими и организационными новациями. С ее позиции видно, что развитие технологии определено типом и поведением человека. Итак, тип человека лежит в основании модернизации. Модернизация становится «видимой», при разделении сетей власти, становится понятной разность способов формирования человека в отдельно взятой культуре, ее способе модернизации, становится понятно, каким образом надо формировать активных работников в рамках данной культуры.

УДК 111.1

Науч. спец. 09.00.13

DOI: $10.36809 / 2309-9380-2020-28-40-44$

\section{ИНФРАУРОВНЕВОЕ ВО ВЗАИМОСВЯЗИ ЛИЧНОСТНОЙ И СОЦИАЛЬНОЙ ХРОНОТОПОЛОГИИ}

В статье исследуется диалектика личностной и социальной форм пространственно-временной структуры человеческого существования в аспекте инфрауровневых явлений, сопровождающих бытие человека. Теоретическим основанием работы выступает концепция хронотопа А. А. Ухтомского и М. М. Бахтина, а методологической базой - семантический и герменевтический анализ произведений советской и российской художественной литературы и публицистики второй половины XX в. В исследовании бытие человека раскрывается как многоуровневая пространственно-временная консригурация, структурными элементами которой выступают, в частности, личностная хронотопология (аксиологически и экзистенциально структурированный микрокосм человеческого существования) и социальная хронотопология (надиндивидуальный макрокосм), находящиеся в сложном неоднозначном взаимоотношении, негативные инфрауровневые проявления которого деформируют личностный мир и жизненный путь человека.

Ключевые слова: хронотоп, время, пространство, личность, человек.
1. Манн М. Источники социальной власти : в 4 т. Т. 1. История власти от истоков до 1760 года н. э. М. : Дело, 2018. $760 \mathrm{c}$.

2. Николин В. В., Федяев Д. М. Техника в потоке истории: Социальные факторы развития техники. Омск - Челябинск : Изд-во ОмГПУ — Изд-во ЧГПУ, 1992. 246 с.

3. Исикава К. Японские методы управления качеством. М. : Экономика, 1988. 215 с.

4. Тоффрлер А. Третья волна. М. : АСТ, 1998. 781 с.

5. Бредберри Т., Гривз Д. Эмоциональный интеллект 2.0. М. : Манн, Иванов и Фербер, 2010. 192 с.

6. Фукуяма Ф. Конец истории и последний человек. М. : ACT, 2005. $588 \mathrm{c}$.

7. Эшелоны модернизации и проблема «догоняющего развития» // istmira.com : [сайт]. URL: https://www.istmira.com/ novejshaya-istoriya/1474-yeshelony-modernizacii-i-problemadogonyayushhego.html (дата обращения: 24.10.2020).

(С) Николин И. В., 2020
А. В. Политов

A. V. Politov

\section{INFRA-LEVEL \\ IN THE RELATIONSHIP OF PERSONAL AND SOCIAL CHRONOTOPOLOGY}

The article examines the dialectics of personal and social forms of the spatiotemporal structure of human existence in the aspect of infra-level phenomena that accompany human existence. The theoretical basis of the work is the concept of the chronotope by A. A. Ukhtomsky and M. M. Bakhtin, the methodological basis is the semantic and hermeneutic analysis of works of Soviet and Russian fiction and journalism of the second half of the $20^{\text {th }}$ century. In the study, human existence is revealed as a multilevel spatiotemporal configuration, the structural elements of which are, in particular, personal chronotopology (axiologically and existentially structured microcosm of human existence) and social chronotopology (supra-individual macrocosm), which are in a complex ambiguous relationship, the negative infra-level manifestations of which deform personal world and life path of a person.

Keywords: chronotope, time, space, personality, human.
В исследовании бытие человеческой личности будет интерпретироваться в качестве хронотопологической (пространственно-временной) структуры, что впервые было разработано и введено в научный оборот А. А. Ухтомским [1, с. 67-71] и М. М. Бахтиным [2, с. 341-503]. Выделим два возможных уровня или формы пространственно-временной организации бытия человека: социальный уровень, проблематика которого разработана в русле понятия социального хронотопа и топологического философствования: [3, с. 109-114; 4, с. 147-159] и личностный уровень. Понятие пространственно-временного мира личности на данный момент исследовано преимущественно в области психо- 